\title{
Bipolaron Hopping Conduction in Boron Carbides
}

\author{
T. L. Aselage, ${ }^{1,2}$ D. Emin, ${ }^{2}$ and S. S. McCready' \\ ${ }^{1}$ Sandia National Laboratories, Albuquerque, NM 87185-1421, USA \\ ${ }^{2}$ Dept. of Physics and Astronomy, University of New Mexico 87131-1156, USA \\ PACS: 71.38.+i, 72.20.Pa, 72.20.-I, Substance Class: S5
}

\begin{abstract}
The electrical conductivities of boron carbides, $\mathrm{B}_{12+\mathrm{x}} \mathrm{C}_{3-\mathrm{x}}$ with $0.1<\mathrm{x}<1.7$, between 300 and $1200 \mathrm{~K}$ suggest the hopping of a nearly temperature-independent density of small (bi)polarons. The activation energies of the mobilities are low, $\approx 0.16 \mathrm{eV}$, and are nearly independent of the composition. At lower temperatures, conductivities have non-Arrhenius temperature dependencies and strong sensitivity to carbon concentration. Percolative aspects of lowtemperature hopping are evident in this sensitivity to composition. Boron carbides' Seebeck coefficients are anomalous in that 1) they are much larger than expected from boron carbides' large carrier densities and 2) they depend only weakly on the carrier density. Carrier-induced softening of local vibrations gives contributions to the Seebeck coefficient that mirror the magnitudes and temperature dependencies found in boron carbides.
\end{abstract}




\section{DISCLAIMER}

This report was prepared as an account of work sponsored by an agency of the United States Government. Neither the United States Government nor any agency thereof, nor any of their employees, make any warranty, express or implied, or assumes any legal liability or responsibility for the accuracy, completeness, or usefulness of any information, apparatus, product, or process disclosed, or represents that its use would not infringe privately owned rights. Reference herein to any specific commercial product, process, or service by trade name, trademark, manufacturer, or otherwise does not necessarily constitute or imply its endorsement, recommendation, or favoring by the United States Government or any agency thereof. The views and opinions of authors expressed herein do not necessarily state or reflect those of the United States Government or any agency thereof. 


\section{DISCLAIMER}

Portions of this document may be illegible in electronic image products. Images are produced from the best available original document. 
Boron carbides, $\mathrm{B}_{12+\mathrm{x}} \mathrm{C}_{3-\mathrm{x}}$ with $0.1 \leq \mathrm{x} \leq 1.7$, are refractory solids having distinctive structures and bonding. Fifteen-atom unit cells comprise twelve-atom, $\left(\mathrm{B}_{11} \mathrm{C}\right)$, icosahedral clusters and three-atom chains. At an idealized stoichiometry of $\mathrm{B}_{12} \mathrm{C}_{3}, \mathrm{x}=0$, each $[\mathrm{CBC}]$ chain donates an electron, $\rightarrow[\mathrm{CBC}]^{+}$, to fill the internal bonding orbitals of $\mathrm{a}\left(\mathrm{B}_{11} \mathrm{C}\right)$ icosahedron, $\rightarrow$ $\left(\mathrm{B}_{11} \mathrm{C}\right)^{-}$. This idealized composition, $\left(\mathrm{B}_{11} \mathrm{C}\right)[\mathrm{CBC}]^{+}$, is an electrical insulator. In realizable boron carbides, $\mathrm{x}>0$, hole-like charge carriers are produced when $\mathrm{B}$ atoms substitute for $\mathrm{C}$ atoms. The value of $x$ thereby fixes the carrier density. Because $x$ is large, boron carbides' intrinsic carrier densities are large: $\approx 10^{21} / \mathrm{cm}^{3}$. Measuring low, activated Hall mobilities and electrical conductivities in boron carbides indicated that these charge carriers move by polaronic hopping. [1] However, a large paramagnetic susceptibility commensurate with boron carbides' high carrier densities was not found. [2] In addition, recent measurements of boron carbides' low-temperature Seebeck coefficients [3] do not find the strong magnetic-field dependence that is expected of unpaired hopping carriers. These experiments indicate that charge carriers in boron carbides pair to form singlet bipolarons.

Emin [4] shows that carrier-induced softening can stabilize singlet pairs occupying degenerate orbitals, such as the frontier orbitals of icosahedra. Bipolarons in boron carbides are believed to occupy icosahedral sites. A simple model relates the concentration of bipolarons to the $\mathrm{C}$ concentration. [5] As $\mathrm{x}$ increases from zero, structural and vibrational measurements [6] and free energy considerations [5] suggest that $B$ atoms first replace $C$ atoms within chains, $C B C$ $\rightarrow \mathrm{CBB}$. A CBB chain, being isoelectronic to a $[\mathrm{CBC}]^{+}$chain, does not donate an electron to an icosahedron. Pairing of the resulting holes may be viewed as an icosahedral disproportionation: $2\left(\mathrm{~B}_{11} \mathrm{C}\right)^{\mathrm{o}} \rightarrow\left(\mathrm{B}_{11} \mathrm{C}\right)^{-}+\left(\mathrm{B}_{11} \mathrm{C}\right)^{+}$, where $\left(\mathrm{B}_{11} \mathrm{C}\right)^{+}$represents a bipolaronic hole. The $\left(\mathrm{B}_{11} \mathrm{C}\right)^{+}$density rises with increasing $\mathrm{CBB}$ chain substitution, reaching a maximum when each chain is $\mathrm{CBB}$ at $\mathrm{x}$ 
$=1,13.3 \% \mathrm{C}$. The $\left(\mathrm{B}_{11} \mathrm{C}\right)^{+}$concentration decreases with further reductions in $\mathrm{C}$ concentration as donating $[\mathrm{BBB}]^{+}$chains progressively replace $\mathrm{CBB}$ chains. $[6,7]$ The bipolaron density is thus a peaked function of $\mathrm{C}$ concentration, reaching its maximum value $\left(1 / 2\right.$ of the $\left(\mathrm{B}_{11} \mathrm{C}\right)$ sites $)$ at 13.3 $\% \mathrm{C}$.

High-temperature (300 - 1775K) conductivities of boron carbides with compositions spanning the single-phase region are plotted in Fig. 1. These conductivities are proportional to the densities of bipolaronic holes described by the model; peaking of the conductivity near 13.3 $\% \mathrm{C}$ is apparent. Additionally, a nearly Arrhenius mobility is evident in the near linearity of $\log (\sigma \mathrm{T})$ vs. $1 / \mathrm{T}$ between 300 and $1200 \mathrm{~K}$. A slight curvature near $500 \mathrm{~K}$ in $\log (\sigma \mathrm{T})$ of highconductivity samples is suggestive of the activation and subsequent exhaustion of some source of additional charge carriers. The low activation energy of the mobility, $\approx 0.16 \mathrm{eV}$, is consistent with the motion of "softening" bipolarons. [4] At very high temperatures, above 1200K, an abrupt increase in the apparent activation energy, to about $0.6 \mathrm{eV}$, indicates the onset of another conduction mechanism.

Fig. 2 displays the conductivities of boron carbides from $300 \mathrm{~K}$ to below $10 \mathrm{~K}$. In this regime, conductivities have both non-Arrhenius temperature dependencies and strong sensitivity to $\mathrm{C}$ concentration. When compositions are near $13.3 \% \mathrm{C}$, bipolaronic holes move among icosahedral sites having nearly uniform surroundings of neutral, CBB, chains. Non-Arrhenius conductivities under these circumstances result primarily from the freezing out of multi-phonon processes. [8] As the $\mathrm{C}$ concentration departs from $13.3 \%$ toward either of its extremes, neutral, CBB chains are replaced by positively charged, $[\mathrm{CBC}]^{+}$or $[\mathrm{BBB}]^{+}$, chains. Coulomb repulsion renders an icosahedral site amid positively charged chains less favorable for a bipolaronic hole than sites amid neutral chains. The number of favorable icosahedral sites thus becomes 
increasingly small and disconnected as $\mathrm{C}$ concentration moves towards either of its extremes. The larger slopes of the conductivities of high- and low-carbon samples at low temperatures reflect the additional freezing out of energetically unfavorable conduction paths.

Fig. 3 shows the Seebeck coefficients, S, of boron carbides measured using several apparatus to cover the temperature range 10 to $900 \mathrm{~K}$. Boron carbides' large carrier densities are expected to yield small values of $S ; S \approx 0$ for site occupancies $\approx 1 / 2$. By contrast, at high temperatures $\mathrm{S}$ is very large, $>180 \mu \mathrm{V} / \mathrm{K}$, for all boron carbides. It is apparent that the major contribution(s) to $\mathrm{S}$ are insensitive to boron carbides' carrier densities. Carrier-induced softening of local vibrations can produce two types of contributions to the Seebeck coefficient, the sum of which have temperature dependencies like those depicted in Fig. 3. [9] These softening effects can be especially large when they accompany the stabilization of singlet bipolarons. [4] The first type of softening contribution is associated with the reduction in local vibrational frequencies upon insertion of a carrier. It rises with increasing temperature to a plateau, as illustrated by the solid lines of Fig. 3. The second type of contribution is associated with the energy transported with a carrier as it hops from a softened, occupied site to an unoccupied site. This contribution is proportional to the differential "activation energy", $E_{A}(T)$, divided by the temperature. As illustrated by the dashed lines of Fig. 3, this transport contribution rises with increasing temperature as $E_{A}(T)$ increases, reaches a maximum value, and then falls as $1 / T$ when $E_{A}(T)$ reaches the (constant) high-temperature activation energy. The sum of these two contributions mirrors the temperature dependence of boron carbides' Seebeck coefficients: rising rapidly with increasing temperature to a peak value, then falling to a large, nearly temperature-independent plateau. [7,9]

This work was supported by the USDOE, OBES, under contract DE-AC04-94AL85000. 


\section{References}

1. C. Wood and D. Emin, Phys. Rev. B 29, 4582 (1984).

2. L. Azevedo, E. Venturini, D. Emin, and C. Wood, Phys. Rev. B 32, 7970 (1985).

3. S. McCready, D. Emin, T. Aselage, and R. Duncan, to be published.

4. D. Emin, these proceedings; D. Emin, submitted to Phys. Rev. B.

5. D. Emin, Phys. Rev. B 38, 6041 (1988).

6. T. Aselage, D. Tallant, and D. Emin, Phys. Rev. B 56, 3122 (1997) and references therein.

7. T. Aselage, D. Emin, S. McCready, and R. Duncan, Phys. Rev. Lett. 81, 2316 (1998).

8. D. Emin, Phys. Rev. Lett. 32, 303 (1974).

9. D. Emin, phys. stat. sol. (b) 205, 385 (1998); D. Emin, Phys. Rev. B, 59, 6205 (1999). 


\section{Figure Captions}

Fig. 1. Conductivities of boron carbides above $300 \mathrm{~K}$.

Fig. 2. Conductivities of boron carbides at low temperatures. Open symbols: $\mathrm{C}$ concentration decreasing from $20 \%$ toward $13.3 \%$. Shaded symbols: C concentration decreasing from $13.3 \%$.

Fig. 3. Seebeck coefficients of boron carbides of 3 compositions spanning the single-phase region. Curves in the central plot illustrate contributions of $S_{\text {vibrations }}$ (solid) and $S_{\text {transport }}$ (dash) for carriers coupling to vibrations of two different energies. 


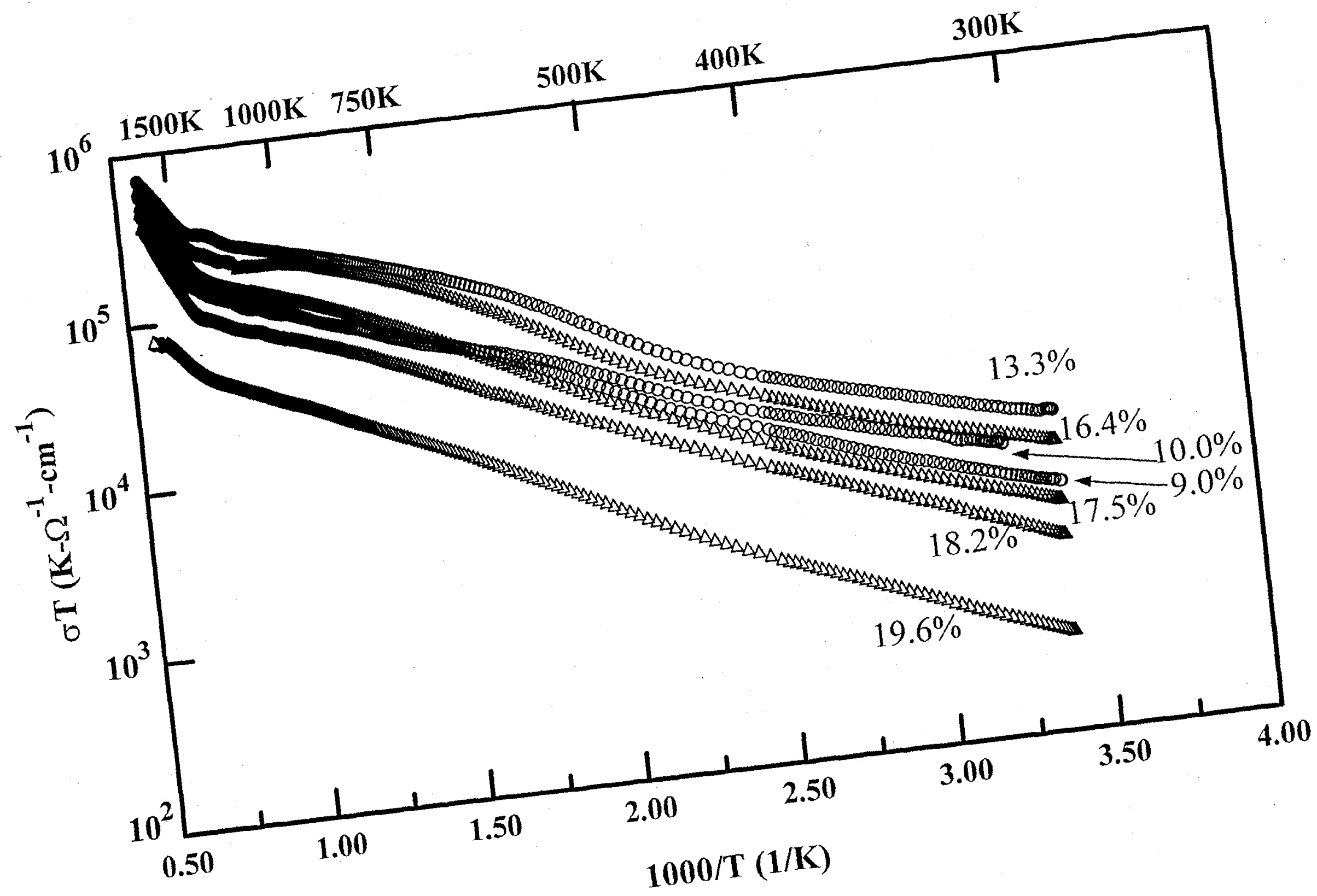




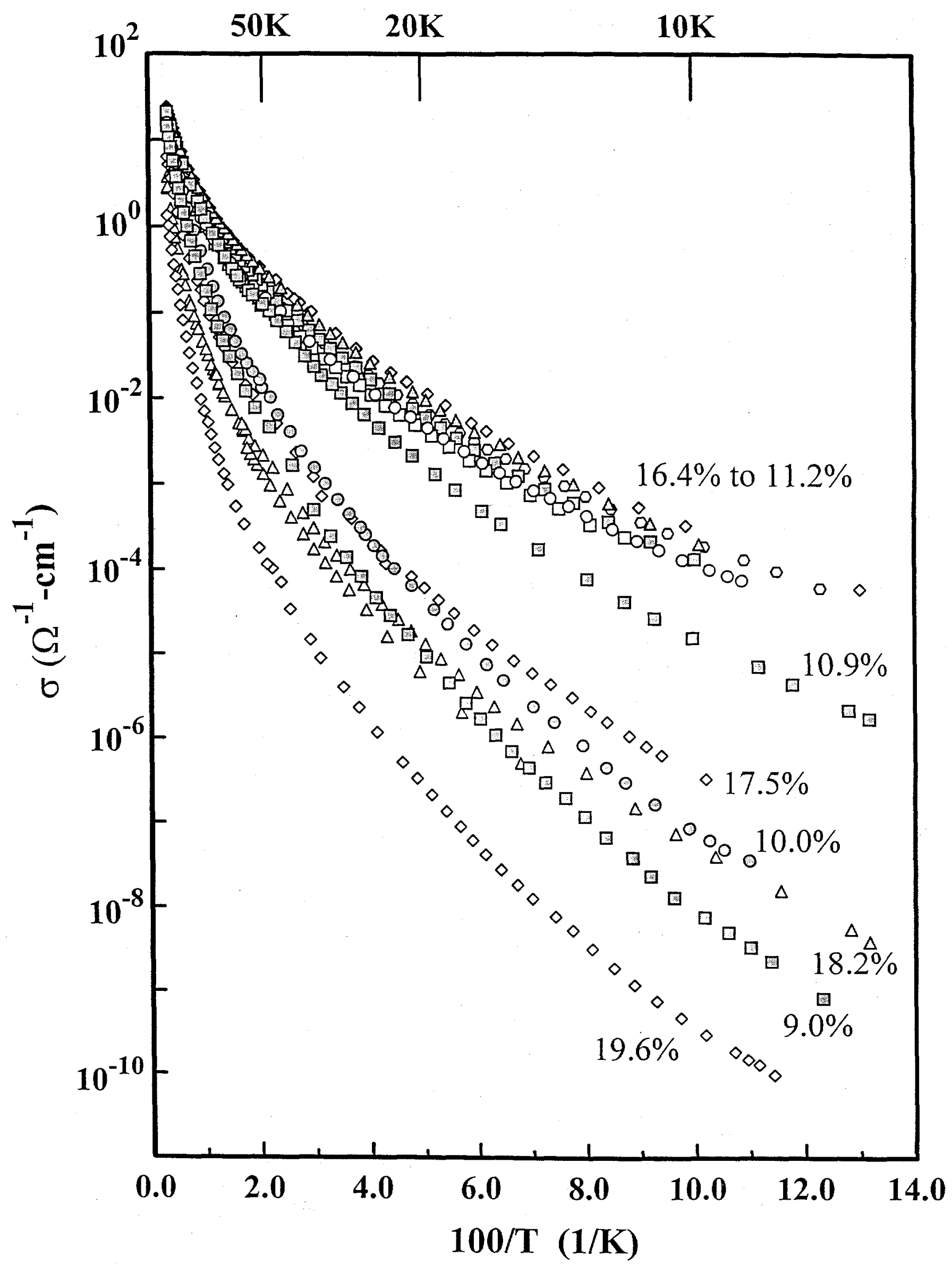




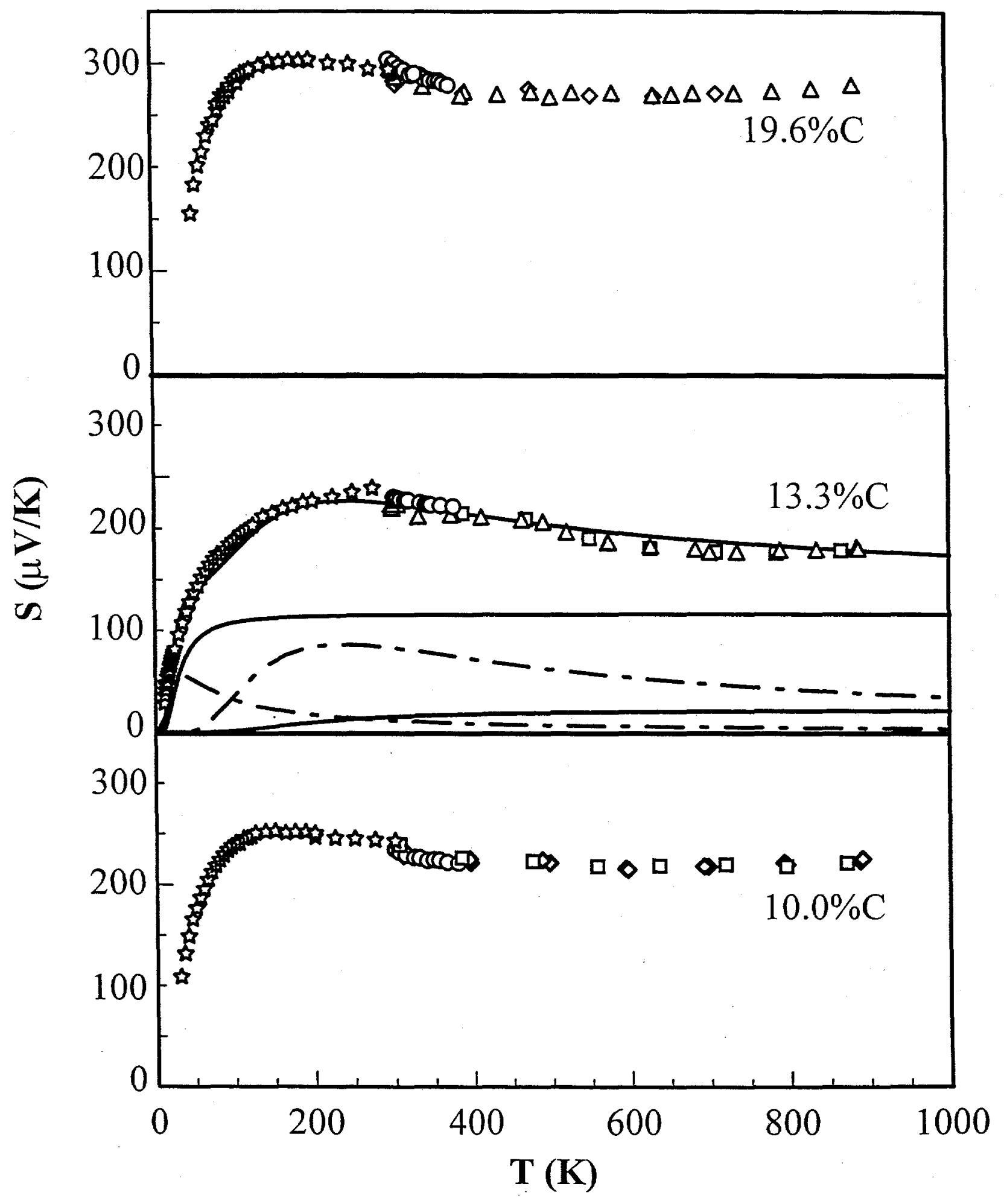

